www.jmscr.igmpublication.org

Index Copernicus Value: 79.54

ISSN (e)-2347-176x ISSN (p) 2455-0450

crossref DOI: https://dx.doi.org/10.18535/jmscr/v7i5.115

\title{
A Study on the efficacy and safety of Myoinositol and Metformin in the treatment of PCOS
}

\author{
Authors \\ Dr Mamta Rani ${ }^{1}$, Prof. Dr Mamta Singh, DGO, M.D. ${ }^{2 *}$ \\ ${ }^{1}$ P.G. Student (Gynae. \& Obs.) \\ ${ }^{2}$ Professor, Department of Obstetrics \& Gynaecology, Nalanda Medical College, Patna \\ *Corresponding Author
}

Prof. Dr Mamta Singh, DGO, M.D.

Department of Obstetrics \& Gynaecology, Nalanda Medical College, Patna

\section{Objective}

Clinical and metabolic data to compare the efficacy of myoinositol and metformin in subjects with polycystic ovarian syndrome (PCOS) are limited. Present study was performed to compare myoinositol and metformin in subjects with PCOS.

\section{Introduction}

Polycystic ovarian syndrome (PCOS) is a complex condition with multisystem endocrinopathy posing a challenge to female fertility. It is the most common cause of menstrual disturbance, ovarian dysfunction, infertility and metabolic disorders including hyperandrogenism, glucose intolerance and insulin resistance in females of reproductive age. It has significant and diverse clinical implications including reproductive (infertility, hyperandrogenism, hirsutism), metabolic (insulin resistance, impaired glucose tolerance, type 2 diabetes mellitus, adverse cardiovascular risk profiles) and psychological features (increased anxiety, depression and worsened quality of life). ${ }^{1}$
As many as $20 \%$ of women with infertility problems (including fecundability and early pregnancy loss) have been diagnosed with PCOS. ${ }^{2}$ It is often called the most common cause of anovulatory infertility in women. ${ }^{3}$ The incidence has increased in recent years due to change in lifestyle and stress. ${ }^{2}$

The aetiopathology of PCOS is not clear but most probably a strong genetic cause influenced by gestational environment and lifestyle appears to be the causative factor. Insulin resistance is seen in $50-70 \%$ of PCOS patients. It plays a key role in the clinical development of PCOS in almost all the women both obese and lean. Insulin resistance causes compensatory hypersecretion of insulin particularly in response to glucose, so euglycemia is maintained at the expense of hyperinsulinemia. ${ }^{4}$

Abnormalities in endocrinologically active compartment i.e. ovaries, adrenal glands, peripheral fat, hypothalamus-pituitary axis may result in hyperandrogenism and anovulation in PCOS. The ovaries are responsible for most consistent hyperandrogenism. Insulin stimulates the ovarian stroma, theca and granulose cells to 
secrete androgens. Liver production of sex hormone binding globulin is also suppressed. ${ }^{5}$

New research in PCOS pathophysiology concludes that genetics, insulin resistance and ghrenlin (a gastric peptide with adipogenic activity) may play an important role. Insulin sensitizers like Metformin, Pioglitazone, troglitazone have been therapeutically used in the management of PCOS as insulin plays the key role in this syndrome ${ }^{6}$ Metformin has been used in PCOS patients with hyperinsulinemia for last several decades in order to improve anovulation, menstrual irregularities and infertility and its related problems. ${ }^{7}$ Metformin in therapeutic dose is responsible for several side effects such as anorexia, nausea, flatulence and diarrhoea, sometimes needs to be discontinued in pregnancy. Myoinositol is one of the most interesting molecules that have been studied for the management of PCOS in recent years. It is a chemical compound with the formula $\mathrm{C}_{6} \mathrm{H}_{12} \mathrm{O}_{6}$. It is naturally found chemical, widely available in many plants and in animal tissue. Fruits, beans, corns and nuts are the food with highest concentration of myoinositol. Administration of D-chiroinositol (intracellularly converted from myoinositol) could reduce the insulin resistance. ${ }^{8}$ In addition, myoinositol intake improves reproductive axis functioning in patients with PCOS, reducing the hyperinsulinaemic state. ${ }^{10}$ In contrast to metformin, no side effects have been reported following treatment with myoinositol ${ }^{11}$. Myoinositol produces a second messenger, Inositol triphosphate that regulates some hormones such as thyroid - stimulating hormone and follicle- stimulating hormone, and is responsible for glucose uptake ${ }^{12}$, which in turn increases insulin sensitivity.

Myoinositol, indeed as a second messenger plays an essential role for the signal pathways of cells. The action of myoinositol would be related to improved insulin sensitivity and a subsequent increased intracellular glucose uptake in particular in PCOS. The aim of this study was to determine the efficacy in the form of pregnancy rates where a combination of myoinositol and folic acid was used in infertile patients with PCOS so as to establish if this molecule can be used as a safer option for the improved pregnancy rate in PCOS.

At present data on comparison of myoinositol and metformin on clinical, metabolic and genetic parameters in subjects with PCOS are very small $^{12}$. Therefore this study was carried to compare myoinositol and metformin on clinical and metabolic parameters in these patients.

\section{Patients and Methods}

A study during June 2017 to August 2018 was done on patients attending the department of Gynaecology \& Obstetrics of Nalanda Medical College, Patna. A total of 100 women with PCOS and infertility were selected and their reports generated according to Rotterdam classification ${ }^{13}$. Out of 100 patients 50 were recommended Myoinositol $2000 \mathrm{mg}$ thrice a day and Folic acid $200 \mu \mathrm{g}$ twice a day and continued for at least 3 months. Another 50 patients were treated with Metformin $1500 \mathrm{mg} /$ day in three divided dosages. The primary outcome of the study was to determine the restoration of ovulatory function and the pregnancy rate following treatment. The secondary outcome was to evaluate the compliance rate and side effects reported in both groups of the patients receiving treatment. In our study the pregnancy outcome was also studied.

\section{Result}

The data of 100 women with PCOS were evaluated. Baseline characteristic like age and BMI were almost similar in both groups.

Table 1: Demographic Details of the Subjects.

\begin{tabular}{|c|c|c|}
\hline \multicolumn{3}{|l|}{ Age Group } \\
\hline Age Group (yrs) & $\begin{array}{c}\text { Group } A(n=50) \\
(\%)\end{array}$ & $\begin{array}{c}\text { Group B } \\
(n=50)(\%)\end{array}$ \\
\hline $15-20$ & $9(18 \%)$ & $8(16 \%)$ \\
\hline $21-25$ & $6(12 \%)$ & $5(10 \%)$ \\
\hline $26-30$ & $15(30 \%)$ & $13(26 \%)$ \\
\hline $31-35$ & $10(20 \%)$ & $11(22 \%)$ \\
\hline $36-40$ & $4(8 \%)$ & $6(12 \%)$ \\
\hline $41-45$ & $6(12 \%)$ & $7(14 \%)$ \\
\hline Total & $50(100 \%)$ & $50(100 \%)$ \\
\hline \multicolumn{3}{|l|}{ BMI $\left(\mathrm{kg} / \mathrm{m}^{2}\right)$} \\
\hline$<24.9$ & $12(24 \%)$ & $14(28 \%)$ \\
\hline 25.29 .9 & $27(54 \%)$ & $26(52 \%)$ \\
\hline $30-34.9$ & $11(22 \%)$ & $10(20 \%)$ \\
\hline
\end{tabular}


In group A, serum fasting insulin level decreased by $51 \%$ but not so in group B $(38 \%)$.

Table 2: Effect on Insulin level

\begin{tabular}{|c|c|c|}
\hline Fasting Insulin & Group A & Group B \\
\hline Before treatment (microU/ml) & 14.34 & 14.35 \\
\hline After treatment (microU/ml) & 7.01 & 8.89 \\
\hline \multicolumn{2}{|c|}{$\begin{array}{l}\text { Significant improvement in insulin Sensitivity } \\
\text { was also observed }\end{array}$} & \\
\hline \multicolumn{2}{|c|}{ Table 3: Glucose Insulin ratio } & \\
\hline Glucose: Insulin Ratio & Group A & Group B \\
\hline Before treatment & 7.85 & 7.82 \\
\hline After treatment & 14.14 & 10.15 \\
\hline
\end{tabular}

There was a significant reduction in Serum testosterone, DHEAS and LH levels and marked improvement in serum estradiol level.

Table 4: Hormonal data before and after treatment with Myoinositol and Metformin.

\begin{tabular}{|l|c|c|c|c|}
\hline \multirow{2}{*}{$\begin{array}{l}\text { Hormonal } \\
\text { Data }\end{array}$} & \multicolumn{2}{|c|}{$\begin{array}{c}\text { For Myo inositol } \\
\text { (Group A) }\end{array}$} & \multicolumn{2}{|c|}{$\begin{array}{c}\text { For Metformin (Group } \\
\text { B) }\end{array}$} \\
\cline { 2 - 5 } & $\begin{array}{c}\text { Before } \\
\text { Treatment }\end{array}$ & $\begin{array}{c}\text { After } \\
\text { Treatment }\end{array}$ & $\begin{array}{c}\text { Before } \\
\text { Treatment }\end{array}$ & $\begin{array}{c}\text { After } \\
\text { Treatment }\end{array}$ \\
\hline $\begin{array}{l}\text { Total } \\
\text { Testosterone } \\
\text { ng/ml }\end{array}$ & 98.67 & 37.39 & 99.42 & 50.31 \\
\hline $\begin{array}{l}\text { Estradiol } \\
\text { pg/ml }\end{array}$ & 85.92 & 92.41 & 88.19 & 81.43 \\
\hline $\begin{array}{l}\text { DHEAS } \mu \mathrm{g} \\
\text { /dL }\end{array}$ & 361.86 & 186.4 & 363.07 & 257.82 \\
\hline LH mIU/ml & 15.22 & 8.95 & 15.87 & 7.9 \\
\hline FSH mIU/ml & 6.93 & 4.96 & 6.72 & 6.64 \\
\hline $\begin{array}{l}\text { LH : FSH } \\
\text { Ratio }\end{array}$ & 2.21 & 1.8 & 2.38 & 2.00 \\
\hline
\end{tabular}

According to obtained records, 75 women experienced an improvement of their menstrual cycle towards ovulatory cycles. A total number of 25 women became pregnant. This result could be achieved in the form of pregnancy after the intake of 2-3 months of Myoinositol and Folic acid. No relevant side effects were reported in the patients taking Myoinositol and Folic acid.

\section{Discussion}

This study could show that a new treatment option for women with PCOS and infertility is available. $70 \%$ of the patients restored ovulation following treatment with Myoinositol 2000 mg thrice a day and Folic acid $200 \mu \mathrm{g}$ twice a day for at least three months. The administration of this molecule improves the glucose uptake by acting as a direct Insulin signaling messenger. It thus improves the insulin resistance and hormonal status, thereby restoring the ovulation process.

There is also marked difference in safety and compliance between myoinositol and metformin as found in this study. The patients on metformin have reported mild to severe gastro-intestinal side effects like abdominal pain, nausea, anorexia and diarrhoea. Myoinositol seems to be a safe and well tolerated drug with comparable efficacy as Metformin. Poor compliance and side effects of Metformin makes it less acceptable. The efficacy, absence of significant side effects, and the fact that myoinositol is a natural component of human diet makes it an attractive insulin sensitizer in PCOS. In recent years many studies have demonstrated that an improvement in ovulation rate and regulation of menstrual cycles was obtained by the combined use of 4 grams of Myoinositol and $400 \mu \mathrm{g}$ of Folic acid. Also in another study, Treatment with $1200 \mathrm{mg} / \mathrm{d}$ of myoinositol for 12 weeks was effective in reducing hormonal, metabolic and oxidative abnormalities in patients with PCOS by improving insulin resistance ${ }^{14 .}$

Gerli et. al could show in a prospective study that the group of patients receiving myo inositol and folic acid experience ovulation in $82 \%$ of the cases whereas in placebo group, it was only $63 \%$. $\mathrm{He}$ also reported a regular menstrual cycle in $70 \%$ of cases with myo inositol and folic acid after 16 weeks of treatment as only $13 \%$ case in placebo group $^{15}$. In a study by Raffone et. al .used Myoinositol $2000 \mathrm{mg}$ and folic acid $200 \mu \mathrm{g}$ twice daily vs Metformin $1500 \mathrm{mg} /$ day and found that number of pregnancies was clearly higher in group $\mathrm{A}^{16}$.

Costantino et. al in his double blinded placebo controlled study found that after 16 weeks of Myoinositol treatment improved the blood pressure, triglyceride, cholesterol, glucose and insulin values after a 75 gram oral GTT significantly ${ }^{9}$. The evaluated hormonal values 
were significantly decreased. Total and free Serum testosterone and Progesterone levels as a marker of ovulation were increased significantly in the group receiving Myoinositol. Kamenov et al studied ovulation induction with Myoinositol alone and with combination with Clomiphene citrate in PCOS patients with insulin resistance. $\mathrm{He}$ also found significant improvement in ovulation induction with Myoinositol alone ${ }^{17}$.

This confirms that myoinositol is not only an effective alternative in the treatment of PCOS patients but also a safe and secure drug as no side effects could be observed in the standard dosages. On the other side easy compliance results in the better outcome in the management of ovulation, hyperandrogenism and metabolic parameters on patients with PCOS.

\section{Reference}

1. Teede H, Deeks A, Moran L. Polycystic ovary syndrome: a complex condition with psychological, reproductive and metabolic manifestations that impacts on health across the lifespan. BMC Med. 2010 Jun 30;8:41. doi: 10.1186/1741-7015-8-41. PubMed PMID: 20591140; PubMed Central PMCID: PMC2909929.

2. Diamanti-Kandarakis E, Kouli C, Tsianateli T, Bergiele A. Therapeutic effects of metformin on insulin resistance and hyperandrogenism in polycystic ovary syndrome. Eur J Endocrinol. 1998;138: 269-274

3. Adams J, Polson DW, Franks S. Prevalence of polycystic ovaries in women with anovulation and idiopathic hirsituism. Br Med J (Clin Res Ed) 1986;293:355-359.

4. Legro RS, Strauss JF. Molecular progress in infertility: polycystic ovary syndrome. FertilSteril. 2002;78:569-576.

doi: 10.1016/S0015-0282(02)03275-2.

5. Doi SA, Al-Zaid M, Towers PA, Scott CJ, Al-Shoumer KA. Ovarian steroids modulate neuroendocrine dysfunction in polycystic ovary syndrome. J Endocrinol Invest. 2005;28:882-892.

6. Croze M L, Soulage C O “ Potential role and therapeutic interests of Myoinositol in metabolic diseases.

7. Mansour A, Hosseini S, Larijani B, et al. Nutrients as novel therapeutic approaches for metabolic disturbances inpolycystic ovary syndrome. EXCLI J. 2016;15:551564.

8. Ozegowska K, Bogacz A, BartkowiakWieczorek J, et al. Association between the angiotensin converting enzymegene insertion/deletion polymorphism and metabolic disturbances in women with polycystic ovary syndrome. MolMed Rep.2016;14:5401-5407.

9. Costantino D, Minozzi G, Minozzi E, et al. Metabolic and hormonal effects of myoinositol in women with polycysticovary syndrome: a double-blind trial. Eur Rev Med Pharmacol Sci. 2009;13:105-110.

10. Genazzani AD, Lanzoni C, Ricchieri F, et al. Myo-inositol administration positively affects hyperinsulinemia and hormonal parameters in overweight patients with polycystic ovary syndrome. Gynecol Endocrinol. 2008;24:139-144.

11. Fruzzetti F, Perini D, Russo M, et al. Comparison of two insulin sensitizers, metformin and myo-inositol, in women with polycystic ovary syndrome (PCOS). Gynecol Endocrinol. 2017;33:39-42.

12. Mehri Jamilian; Pegah Farhat; Fatemeh Foroozanfard; Faraneh Afshar Ebrahimi; Esmat Aghadavod; Fereshteh Bahmani; Bita Badehnoosh; Hamidreza Jamilian; Zatollah Asemi Clin Endocrinol. 2017;87(2):194-200.

13. Rotterdam ESHRE/ASRM-Sponsored PCOS consensus workshop group. (2003) Revised 2003 consensus on diagnostic criteria and long term health risks related to polycystic ovary syndrome (PCOS). Human Reproduction, 19, 41-47. 
14. Dona G, Sabbadin C, Fiore C, et al. Inositol administration reduces oxidative stress in erythrocytes of patients with polycystic ovary syndrome. Eur $J$ Endocrinol. 2012;166:703-710.

15. Gerli S, Papaleo E, Ferrari A, et al. Randomized, double blind placebocontrolled trial: effects of myo-inositol on ovarian function and metabolic factors in women with PCOS. Eur Rev Med Pharmacol Sci. 2007;11:347-354.

16. Raffone E, Rizzo P, Benedetto V. Insulin sensitizer alone and in co treatmeny with $\mathrm{r}$ FSH for ovulation induction in PCOS women: Gynaecol. Endocrinol. 2010, 26:275-280.

17. Ovulation induction with myo-inositol alone and in combination with clomiphene citrate in PCOS with insulin resistance. Gynaecol. Endocrinol. 2015, 31(2): 13-15. 